\title{
САХАРНЫЙ ДИАБЕТ И COVID-19: ОЦЕНКА РИСКА ЛЕТАЛЬНОСТИ ПО ДАННЫМ ФЕДЕРАЛЬНОГО РЕГИСТРА САХАРНОГО ДИАБЕТА
}

\author{
Шестакова М.В., Мокрышева Н.Г., Викулова О.К., Айнетдинова А.Р., Исаков М.А., Дедов И.И.
}

\author{
ФГБУ «НМИЦ эндокринологии» Минздрава России, Москва
}

ЦЕЛь: пандемия коронавирусной инфекции внесла крайне негативный вклад в аспекты ведения пациентов с сахарным диабетом (СД), ставших «мишенью» вируса как в плане более тяжелого течения COVID-19, так и повышения риска неблагоприятных исходов. Оценка исходов течения в данной популяции представляет важнейшее значение для анализа факторов риска развития летального исхода. Целью исследования является анализ уровня и факторов летальности у пациентов с СД в РФ, перенесших COVID-19.

МАТЕРИАЛЫ И МЕТОДЫ: объект исследования - база данных Федерального регистра СД (http://diaregistry.ru), 84 региона РФ. В анализ были включены 156950 пациентов с СД (7751 пациент с СД 1 типа (СД1) и 149199 - с СД 2 типа (СД2) с указанием в регистре о перенесенной ОРВИ/пневмонии вследствие COVID-19 в период с 01.02.2020 г. и исхода заболевания (смерть/выздоровление), выгрузка данных от 20.05.2021. Риск летальности оценивался по отношению шансов (ОШ), с повышением риска при ОШ >1, 95\% доверительному интервалу (ДИ), критерий значимости<0,05.

РЕЗУЛЬТАТЫ: летальность вследствие COVID-19 в общей популяции СД составила 12,4\%, при СД1 и СД2 - 7,2\% и 12,6\% соответственно. При обоих типах СД уровень летальности зависел от пола, возраста и длительности СД, значимыми факторами риска были: мужской пол, возраст $\geq 65$ лет, длительность СД $\geq 10$ лет. Летальность составила: муж/жен - СД1 8,4\%/6,0\% (ОШ=1,44 [95\% ДИ: 1,21-1,72], р<0,001); СД2 14,8\%/11,6\% (ОШ=1,31 [95\% ДИ: 1,27-1,36], р<0,001); возраст $\geq 65 /<65-$ СД1 19,0\%/6,1\% (ОШ=3,62 [95\% ДИ: 2,91-4,50], р<0,001), СД2 17,8\%/6,5\% (ОШ=3,09 [95\% ДИ: 2,99-3,20], р<0,001); СД $\geq 10 /<10$ лет Сд1 8,6\%/4,2\% (ОШ=2,16 [95\% ДИ: 1,73-2,69], р<0,001), СД2 17,8\%/9,3\% (ОШ=2,11 [95\% ДИ: 2,04-2,17], $\mathrm{p}<0,001)$.

При детальном анализе летальности в различных возрастных группах были выявлены следующие статистически значимые различия: при СД1 в возрасте $<40$ лет летальность составила 3,8\%, 40-59 лет - 7,3\%, 60-79 лет - 16,3\%, >80 лет - 42,9\% (р<0,001); СД2: <40 лет - 3,19\%, 40-59 лет - 5,3\%, 60-79 лет - 13,0\%, $>80$ лет - 30,7\% (p<0,001).

При $\mathrm{HbA}_{1 c}<7 \% / \geq 7 \%$ летальность составила при СД1: 3,0\%/3,4\% (p=0,502); СД2: 4,0\%/5,7\% (ОШ=1,44

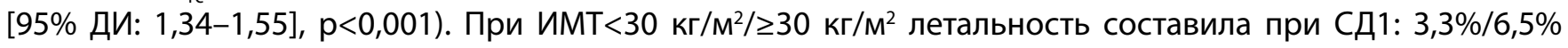
(ОШ=2,02 [95\% ДИ: 1,48-2,78]; p<0,001); СД2: 5,6\%/5,6\% при ИМТ $\geq 30$ кг/м² (р=0,895). Детальный анализ

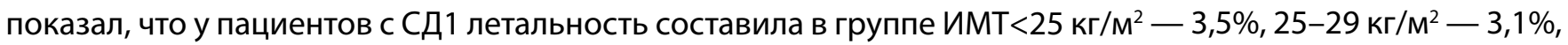

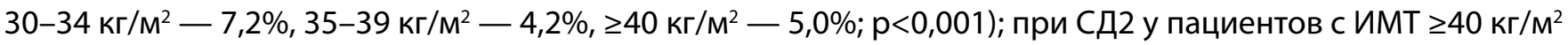
летальный исход COVID-19 наблюдался чаще $(6,48 \%)$ по сравнению с остальными группами (<25 кг/м²-

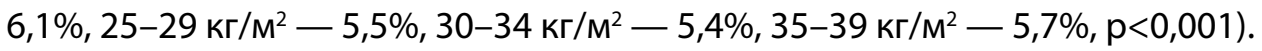

Факторами риска летальности вследствие COVID-19 у пациентов с СД1 было наличие сосудистых осложнений хронической болезни почек (ХБП) и сердечно-сосудистых заболеваний (ССЗ). В группе пациентов с ХБП летальность была в 2 раза выше, чем у пациентов без ХБП (9,6\%/5,3\%, ОШ=1,89 [95\% ДИ: 1,59-2,25]; p<0,001); наличие CC3 также негативно влияло на прогноз COVID-19 (10,2\%/5,6\%, ОШ=1,91 [95\% ДИ: 1,60-2,27]; $p<0,001)$.

При СД2 уровень летальности был выше на терапии инсулином (15,7\%/11,5\%, ОШ=1,44 [95\% ДИ: 1,39-1,49]; р<0,001) и препаратами сульфонилмочевины (СМ) (14,2\%/11,5\%, ОШ=1,28 [95\% ДИ: 1,24-1,31]; р<0,001). Пациенты, принимающие метформин (10,8\%/17,7\%, ОШ=0,56 [95\% ДИ: 0,54-0,58]; p<0,001), ингибиторы дипептидилпептидазы-4 (иДПП-4) (8,2\%/13,3\%, ОШ=0,58 [95\% ДИ: 0,55-0,61]; р<0,001), ингибиторы натрий-глюкозного котранспортера 2 типа (иНГЛт2) (6,5\%/13,1\%, ОШ=0,46 [95\% ДИ: 0,42-0,50]; $\mathrm{p}<0,001)$, агонисты рецепторов глюкагоноподобного пептида 1 (арГПП1) (5,2\%/12,7\%, ОШ=0,38 [95\% ДИ: 0,53-0,57]; р<0,001), имели меньшие показатели летальности.

Летальность пациентов с СД2, получающих терапию ингибиторами ангиотензинпревращающего фермента (иАПФ)/блокаторами рецепторов ангиотензина II (БРА)), составила 5,0\% против 11,7\% при 
отсутствии органопротективной терапии (ОШ=0,40 [95\% ДИ: 0,37-0,44]; $p<0,001$ ), в популяции с СД2 и наличием ССЗ и/или ХБП: 11,6\% против 12,0\% (ОШ=0,96 [95\% ДИ: 0,92-1,00]; p=0,054).

Выводы: таким образом, была выявлена совокупность факторов летальности вследствие COVID-19 при СД: мужской пол, возраст старше 65 лет, длительность СД более 10 лет; факторами риска являлись основные метаболические показатели: $\mathrm{HbA}_{1 с} \geq 7 \%$ при СД2 и ИМТ $\geq 30$ кг/м² при СД1. При СД1 значимое повышение риска смерти ассоциировалось с наличием сочетанной патологии: ССЗ и ХБП; при СД2 с характером сахароснижающей терапии: терапия инсулином и СМ являлись факторами риска, терапия метформином, иДПП-4, иНГЛТ2 и арГПП1, напротив, снижала риски смертности. Защитным фактором при СД2 был прием органопротективной терапии иАПФ/БРА, что снижало риск летального исхода в общей популяции СД2 на 60\%, у пациентов с СД и ССЗ и/или ХБП — на 4\%.

КЛЮЧЕВЫЕ СЛОВА: сахарный диабет; COVID-19; летальность; гликированный гемоглобин. 